\title{
Hydroxy decenoic acid down regulates gtfB and gtfC expression and prevents Streptococcus mutans adherence to the cell surfaces
}

\author{
Behnam Yousefi ${ }^{1+}$, Shahrooz Ghaderi ${ }^{2}$, Alireza Rezapoor-Lactooyi ${ }^{1}$, Niusha Amiri ${ }^{3}$, Javad Verdi ${ }^{4,5}$ and
} Alireza Shoae-Hassani ${ }^{5^{*}}$

\begin{abstract}
Background: 10-Hydroxy-2-decenoic acid, an unsaturated fatty acid is the most active and unique component to the royal jelly that has antimicrobial properties. Streptococcus mutans is associated with pathogenesis of oral cavity, gingivoperiodontal diseases and bacteremia following dental manipulations. In the oral cavity, S. mutans colonize the soft tissues including tongue, palate, and buccal mucosa. When considering the role of supragingival dental plaque in caries, the proportion of acid producing bacteria (particularly S. mutans), has direct relevance to the pathogenicity of the plaque. The genes that encode glucosyltransferases ( $g t f s$ ) especially gtfB and gtfC are important in S. mutans colonization and pathogenesis. This study investigated the hydroxy-decenoic acid (HDA) effects on gtfB and gtfC expression and S. mutans adherence to cells surfaces.

Methods: Streptococcus mutans was treated by different concentrations of HPLC purified HDA supplied by Iran Beekeeping and Veterinary Association. Real time RT-PCR and western blot assays were conducted to evaluate gtfB and gtfC genes transcription and translation before and after HDA treatment. The bacterial attachment to the cell surfaces was evaluated microscopically.
\end{abstract}

Results: $500 \mathrm{\mu g} \mathrm{ml}^{-1}$ of HDA inhibited gtfB and gtfC mRNA transcription and its expression. The same concentration of HDA decreased $60 \%$ the adherence of $S$. mutans to the surface of P19 cells.

Conclusion: Hydroxy-decenoic acid prevents gtfB and gtfC expression efficiently in the bactericide subconcentrations and it could effectively reduce $S$. mutans adherence to the cell surfaces. In the future, therapeutic approaches to affecting S. mutans could be selective and it's not necessary to put down the oral flora completely.

Keywords: Biofilm, Caries, Glucosyltransferase, Streptococcus

\section{Background}

Oral streptococci are important components of the complex oral biofilm known as dental plaque. Members of the Streptococcus genus including Streptococcus mutans are associated with dental caries [1,2]. In the oral cavity, organisms colonize the tongue, palate, and buccal mucosa $[3,4]$. Streptococcus mutans strains have been recovered from the subgingival crevice, a well studied microbial niche [5-7]. The ability of bacteria to

\footnotetext{
* Correspondence: nanobiotechnology@ymail.com

${ }^{\dagger}$ Equal contributors

${ }^{5}$ Tissue Engineering and Stem cell department, Research center for Science and Technology in Medicine (RCSTiM), Tehran University of Medical Sciences (TUMS), P.O.Box: 1998896953, Tehran, Iran

Full list of author information is available at the end of the article
}

colonize the different oral surfaces depends on their binding potential. When considering the role of supragingival dental plaque in dental caries, the proportion of gram positive acid producing bacteria (particularly $S$. mutans), has direct relevance to the pathogenicity of the plaque. These microorganisms tolerate a low $\mathrm{pH}$ environment, and thrive in cariogenic substrates such as sucrose [8]. The most frequent oral infections include gingivoperiodontal diseases including gingivitis and periodontitis, are caused by dental plaque, which is a S. mutans produced biofilm [9-11]. The primary mechanism for adherence of $S$. mutans is the production of glucan polymers from sucrose via glucosyltransferases (Gtf) [12] that is an essential virulence factor associated

\section{Biomed Central}


with the pathogenesis of $S$. mutans [13]. Hence, the factors influencing expression of $g t f$ genes are very important for prevention of dental plaques, caries, gingivitis, gingival abscess and even bacteremia following dental manipulation. Glucosyltransferases encoded by $g t f B$ and $g t f C$ genes show similarities. GtfB is an exoenzyme involved with the extracellular metabolism of Sucrose [14]. GtfB synthesizes a polymer of mostly insoluble $(\alpha-1,3$-linked) glucan and $\mathrm{GtfC}$ synthesizes a mixture of insoluble ( $\alpha$-1,3-linked) and soluble ( $\alpha$-1,6-linked) glucans $[15,16]$. These glucans are important components of the matrix of cariogenic biofilms.

The $\mathrm{pH}$ of the all experiments set between (7-7.5). "Significant differences were tested by analysis of variance (ANOVA). $\mathrm{p} \leq 0.05$

10-Hydroxy-2-decenoic acid (HDA) is an important part of royal jelly. Royal jelly (RJ) so called because it is the exclusive food of the Queen bees, which secreted by the hypopharyngeal and mandibular glands of Apis mellifera bees to feed the queen [17]. RJ is a natural source of essential amino acids, lipids, vitamins, acetylcholine, and many other nutrients $[18,19]$. It has a wide range of medical activities such as antimicrobial effects $[20,21]$ and preventing cell damage in cancer and HIV patients [22,23]. The potency of antibacterial properties of RJ is related to HDA [24,25], a bioactive component that occupies $10 \%$ of the RJs total weight. The structure of HDA is depicted in Figure 1. HDA is capable to induce the dispersion of $S$. mutans biofilm microcolonies. HDA is highly acidic and acts as a detergent and antimicrobial agent [26]. It has antitumor [27] and collagen production activities [28]. It is known as a safe natural product, thus here we investigated the HDA effect on $g t f B$ and $g t f C$ expression and consequently adherence of $S$. mutans colonies on the eukaryotic cell surfaces.

\section{Methods}

\section{Preparation of HDA and bacterial treatment}

HPLC purified 10-hydroxy-2-decenoic acid (Figure 1) were provided by Iran Beekeeping and Veterinary Association (Tehran, Iran). Streptococcus mutans ATCC 25175 was purchased from Persian Type Culture Collection (PTCC, Tehran, Iran). The strain was cultured in Brain Heart Infusion broth, (BHIB Difco, Detroit, USA) at $37^{\circ} \mathrm{C}$ with $5 \%$ defibrinated sheep blood in an

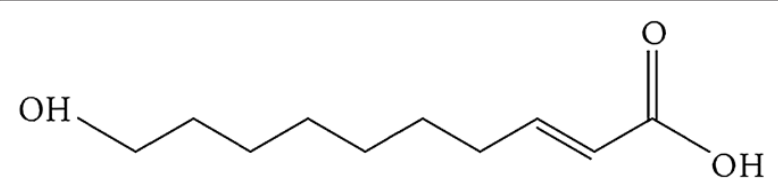

Figure 1 The structure of Trans 10-Hydroxy-2-Decenoic acid (HDA) from Royal jelly. atmosphere containing $5 \% \mathrm{CO}_{2}$. For treatment the cultures were supplied by addition of $100 \mathrm{mM}$ sucrose (Merck, Germany). The early exponential phase cultures $(\mathrm{pH}$ 6.8) were treated with 100, 200, 500 and $1000 \mu \mathrm{g} \mathrm{ml}^{-1}$ of ethanol dissolved HDA (treatment in peptone buffer, Difco) in $2 \mathrm{ml}$ microtubes during 8 hours and then transferred to the previous media. Untreated peptone water was used as a control. The bacterial growth was determined by measuring the optical densities (OD) at $600 \mathrm{~nm}$. OD was monitored at $1 \mathrm{~h}$ intervals. From the point that HDA is an acidic compound and it may kill the bacteria by the $\mathrm{pH}$ changes we controlled the $\mathrm{pH}(7-7.5)$ by $\mathrm{NaHCO} 3$ and $\mathrm{NaOH}$ buffer. The treated cells extracted by centrifugation $(10 \mathrm{~min}$ at $1000 \mathrm{~g}$ ) for other examinations. The culture supernatant was also examined for $\mathrm{GtfB} / \mathrm{GtfC}$ extracellular enzyme analysis.

\section{Time-kill assays}

Time-kill study was performed by the broth dilution method [29]. The inoculum of $S$. mutans was $1^{\times} 10^{6} \mathrm{CFU} /$ $\mathrm{ml}$. The final concentration of the HDA was four times the MIC (2000 $\left.\mathrm{g} \mathrm{m} \mathrm{m}^{-1}\right)$. Tubes containing the microorganisms and the HDA in BHIB were incubated in 5\% $\mathrm{CO}_{2}$ at $37^{\circ} \mathrm{C}$; samples were removed for determination of viable counts at $30 \mathrm{~min}$ and 1, 2, 4, 8, and $24 \mathrm{~h}$. Serial dilutions $\left(10^{-1}\right.$ to $\left.10^{-4}\right)$ were prepared in sterile saline solution. The diluted sample $(50 \mu \mathrm{l})$ was plated onto Brain heart infusion agar (BHIA) with a spiral plater (Model 3000; Spiral Biotech, Bethesda, US). The plates were incubated in $5 \% \mathrm{CO}_{2}$ for $48 \mathrm{~h}$, when the number of colonies was determined. Killing curves were constructed by plotting the $\log 10 \mathrm{CFU}$ per milliliter over $24 \mathrm{~h}$. All of the assays were done in triplicate.

Evaluation of $g t f B$ and $g t f C$ expression via Real time RT-PCR Total RNA from treated cultures of $S$. mutans were extracted and purified using the RNeasy kit (Qiagen, Germany) followed by digestion with RNase free DNase-I according to the manufacturer's instruction. The cDNA were synthesized using a cDNA synthesis kit (Bio-Rad Lab, US). To check for DNA contamination, purified RNA without reverse transcriptase served as a negative control. The expression of related genes was quantified using the SYBR green reagent (2X SYBR Green Supermix; Bio-Rad, CA) following the instructions of the manufacturer on a Bio-Rad iCycler. PCR was performed in multiplicate in optimized conditions: $95^{\circ} \mathrm{C}$ denatured for $3 \mathrm{~min}$, followed by 40 cycles of $45 \mathrm{~s}$ at $94^{\circ} \mathrm{C}, 45 \mathrm{~s}$ at $55^{\circ} \mathrm{C}$, and $45 \mathrm{~s}$ at $72^{\circ} \mathrm{C}$ using the following primers: $g t f B$ (F: $5^{\prime}$-CGAACAGCTTCTAA TGGTGAAAAGCTT- 3', R: 5'-TTGGCTGCATTGC TATCATCA-3') and $g t f C$ (F: 5'-GCCACGGAACA AGCAGTTCTGTAA- 3', R: 5'-TAATACCAATTAT 
TTCCTAAGCTAA-3')(NCBI sequence Ref No. NC004350). Fluorescence signals were measured over 40 PCR cycles. The cycle number $(C t)$ at which the signals crossed a threshold set within the logarithmic phase was recorded. For quantitation, we evaluated the difference in cycle threshold $(\Delta C t)$ between the treated group and vehicle control of each gene. The efficiency of amplification of each pair of primers was determined by serial dilutions of templates and all were $>0.9$. Each sample was normalized with the loading reference $16 \mathrm{~S}$ rRNA (NCBI sequence Ref No. X58303). Experiments were repeated at least three times.

\section{Western blot analysis of GtfB and GtfC}

Streptococcus mutans cultures grown with the various concentrations of HDA (100-1000 $\mathrm{g} \mathrm{ml}^{-1}$ ) were centrifuged $5 \mathrm{~min}$ at $5000 \mathrm{~g}$. The pellets were resuspended in Tris $\mathrm{HCl} 30 \mathrm{mM}, \mathrm{pH} 8.1$ and centrifuged $10 \mathrm{~min}$ at $10000 \mathrm{~g}$. The pellets were vortexed in $200 \mu \mathrm{l}$ sucrose $20 \%$ in Tris $\mathrm{HCl}$. These cells were resuspended in phosphate buffer $(\mathrm{pH} 7)$ and were incubated on ice with $33 \mathrm{mg} / \mathrm{L}$ lysozyme for $30 \mathrm{~min}$ and then were disrupted by sonication for 20s. After centrifugation for $15 \mathrm{~min}$ at $15000 \mathrm{~g}$, $100 \mu \mathrm{l}$ aliquot of the supernatant was mixed in sample buffer as described previously [30] on $15 \%$ polyacrylamide gel electrophoresis. Final detection of GtfB and $\mathrm{GtfC}$ enzymes was driven by western blot analysis using goat anti-rabbit IgG conjugated with HRP (Dakopatts, Glostrup, Denmark).

\section{Streptococcus mutans adherence assay to P19 cells and antibiotic protection assay}

P19 embryonic cells purchased from Pasture Institute cellular bank (Tehren, Iran) were maintained in Dulbecco's modified Eagle's Medium (DMEM,Gibco, UK) supplemented with $10 \%$ fetal calf serum (FCS, Gibco, UK). Cells were plated at $10^{5}$ cells/well in six well plates coated with collagen. After 1 day of incubation, the cells were examined under a phase-contrast microscope for morphological changes. Five areas, each containing minimum 100 cells, were randomly selected in each well, and were counted. Cell proliferation was evaluated by counting the total cell number after treatment with different concentrations of HDA [31]. Prior to infection, S. mutans $\left(10^{6} \mathrm{CFU}\right.$ per $\mathrm{ml}$ in $\mathrm{BHI}$ ) were mixed either with $100 \mathrm{ml} \mathrm{FCS}$ and $100 \mathrm{ml} \mathrm{BHI}$ and incubated at $37^{\circ} \mathrm{C}$ for $1 \mathrm{~h}$. The bacterial mixtures were centrifuged at $5000 \mathrm{~g}$ for $5 \mathrm{~min}$. The pellets were washed once with PBS and resuspended in DMEM. To determine the number of bacteria that were able to reach inside the cell, antibiotic protection assay was performed as described previously [32]. After $2 \mathrm{~h}$ of coculturing P19 with S. mutans, the wells were washed three times with fresh DMEM/F12 without antibiotics to remove planktonic bacteria. One milliliter of DMEM/F12 containing $300 \mu \mathrm{g} / \mathrm{ml}$ gentamicin and $10 \mu \mathrm{g} / \mathrm{ml}$ penicillin was added to the wells and incubated for $3 \mathrm{~h}$ at $37^{\circ} \mathrm{C}$ in a $5 \% \mathrm{CO} 2$ atmosphere to eliminate extracellular bacteria. Next, the wells were washed 3 times with PBS without antibiotics and the P19 cells were lysed by PMSF in $1 \mathrm{ml}$ of $\mathrm{dH}_{2} \mathrm{O}$ for 20 min. The mixture of lysed P19 cells and free bacteria was collected from the wells and serially diluted in PBS, followed by plating onto BHI agar and incubation at $37^{\circ} \mathrm{C}$ in a $5 \% \mathrm{CO} 2$ atmosphere. After 2 days, the CFUs were counted and the percentage of intracellular bacteria relative to the initial inoculum was calculated. Each experiment was performed in triplicate under standard conditions.

\section{Statistical analysis}

The analysis of data was performed by ANOVA using SPSS 11.0. Differences were considered to be statistically significant when a value of $\mathrm{P} \leq 0.05$ was obtained.

\section{Results}

\section{Time kill kinetic assay}

The result of the time-kill study is shown in Figure 2. HDA in $1000 \mu \mathrm{g} \mathrm{ml}^{-1}$ rapidly reduced the viable counts of $S$. mutans within $1 \mathrm{~h}$ of incubation (reduction of 1 $\log$ in the number of CFU). It has shown bactericidal effects (a >3log decrease in the CFU) on S. mutans for $8 \mathrm{~h}$ of incubation (Figure 2). All the experiments were in $\mathrm{pH}$ ranged between $7-7.5$ by the buffer system as described in methods.

\section{Real Time RT PCR analysis}

We performed real time RT-PCR experiments to examine the abundance of $g t f B$ and $g t f C$ specific mRNA in $S$. mutans cells treated with HDA (Figure 3) Equal

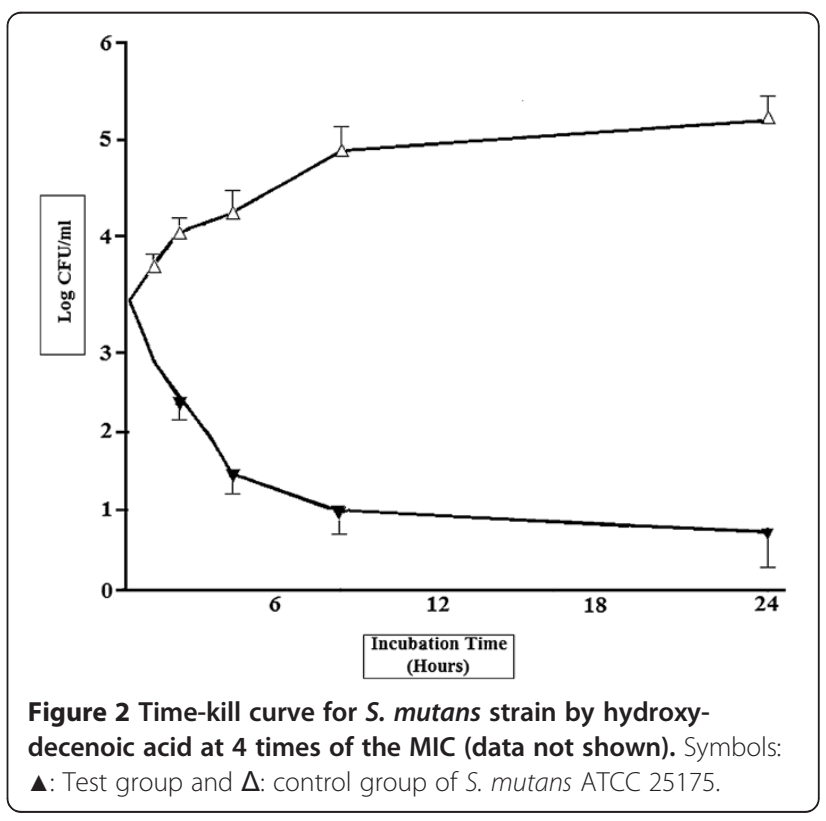




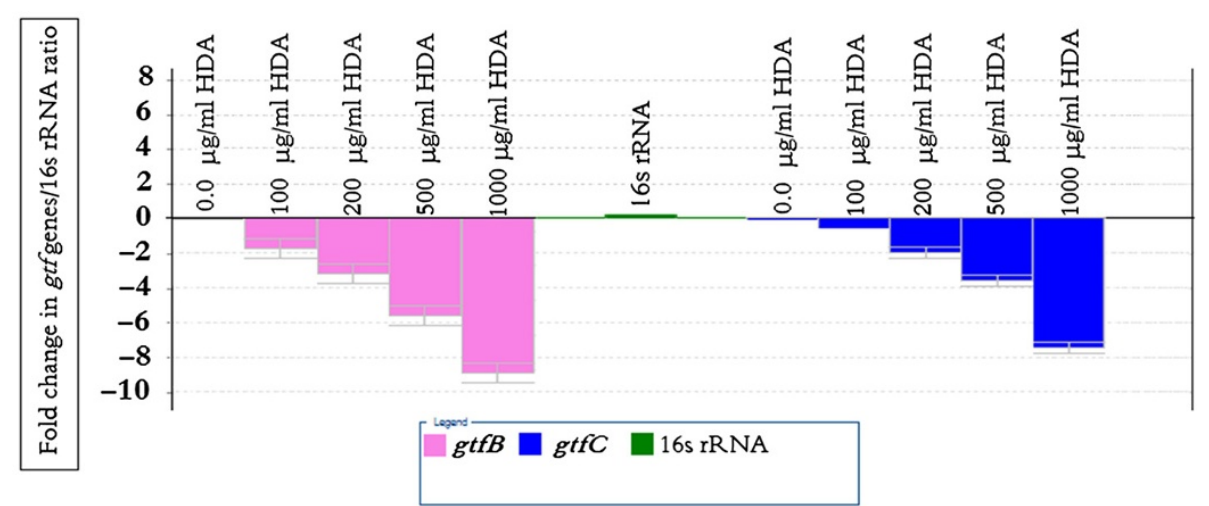

Figure 3 Transcription of $g t f B / g t f C$ from S. mutans following HDA treatment. gtfB/gtfC expression is completely abrogated by exposure to HDA. gtfB/gtfC levels are also reduced with lower concentrations of HDA. The error bars represent mean and standard deviations of experiments performed in triplicate. gtf genes were more abundantly expressed in cultures that treated with $0.0,100$ and $200 \mu \mathrm{g} \mathrm{ml^{-1 }}$ of HDA but missing in the cells treated with $1000 \mathrm{\mu g} \mathrm{ml}^{-1}$ of HDA.

amounts of total RNA from early exponential phase cultures were used to reveal the transcript levels of $g t f B /$ $g t f C$ before and after HDA treatments. The analysis revealed that the $g t f s$ were more abundantly expressed in untreated cultures. No significant difference of $g t f C$ mRNA transcripts was observed among different treatment groups from 0.0 to $100 \mu \mathrm{g} \mathrm{ml}-1$ of HDA. While $500 \mu \mathrm{g} \mathrm{ml}-1$ of HDA greatly inhibited $g t f B$ and $g t f C$ transcription (Figure 3).

\section{Glucosyltransferases analysis by Western blot}

In order to verify whether change in expression of the $g t f B / g t f C$ at the transcriptional level could be duplicated at the protein levels, the intra and extracellular proteins were prepared from cultures of bacteria grown in the enriched BHI medium before and after HDA treatment analyzed by the western blot using goat anti-rabbit IgG. The strength of GtfB and GtfC bands of different treatment groups were revealed as shown in Figure 4. Concentration of $500 \mu \mathrm{g} \mathrm{ml}^{-1}$ of HDA could repress the production of Gtfs completely but the Gtfs production was observed in the samples treated with $200 \mu \mathrm{g} \mathrm{ml}^{-1}$ or lower concentrations as expected from transcription analysis (Figure 4). Therefore, the expression of $g t f B$ and $g t f C$ in response to HDA was consistent at the transcriptional and translational levels.

\section{Adherence to P19 cells}

It was obvious that HDA could slightly reduce P19 embryonal carcinoma cell proliferation and there is a significant difference when compared with PBS control cultures (Figure 5A,B). Also HDA could differentiate the cells phenotype into neural cells but it didn't show major cytotoxicity effects on the cells (Figure 5A) as compared by intact P19 cultures (Figure 5D). Our examination showed that $500 \mathrm{\mu g} \mathrm{ml}^{-1}$ of HDA prevented adhesion of $S$. mutans to the P19 cell surfaces effectively (Figure 5C) as compared by untreated S. mutans cultures (Figure 5B). Concentrations of 100, 200, 500 and $1000 \mu \mathrm{g} \mathrm{ml}^{-1}$ of HDA prevent 12,31, 59 and $61 \%$ of $S$.

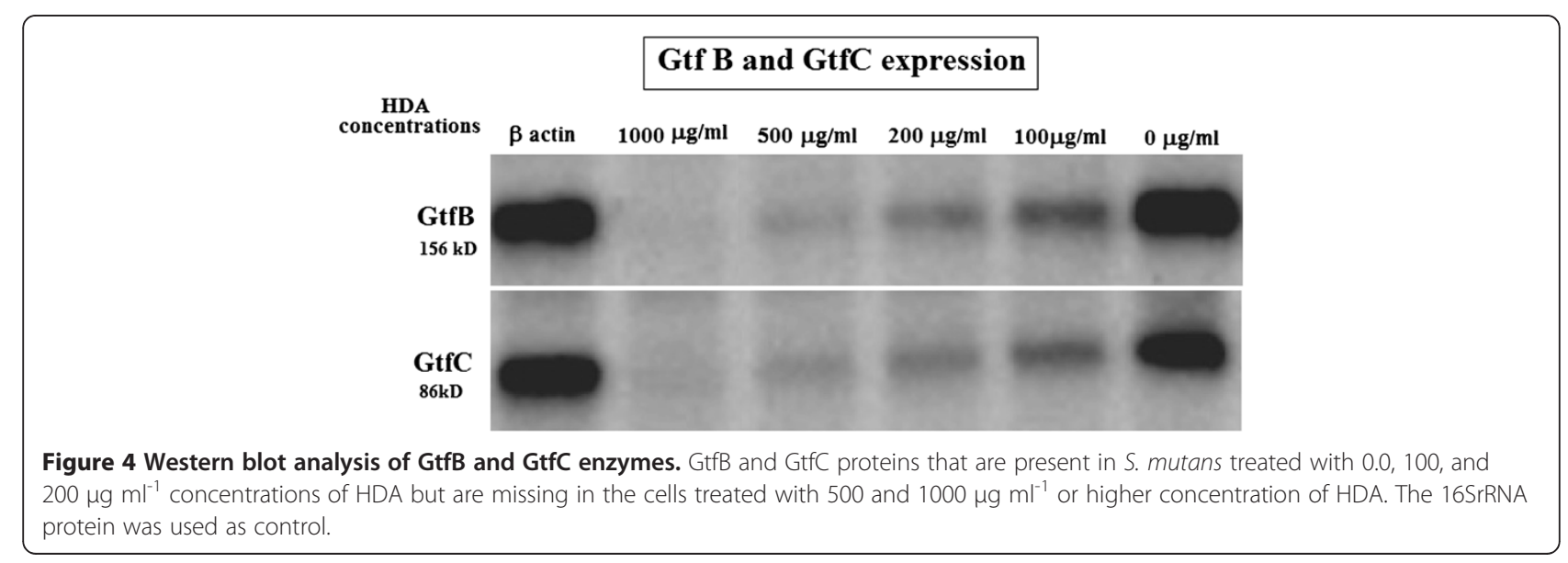



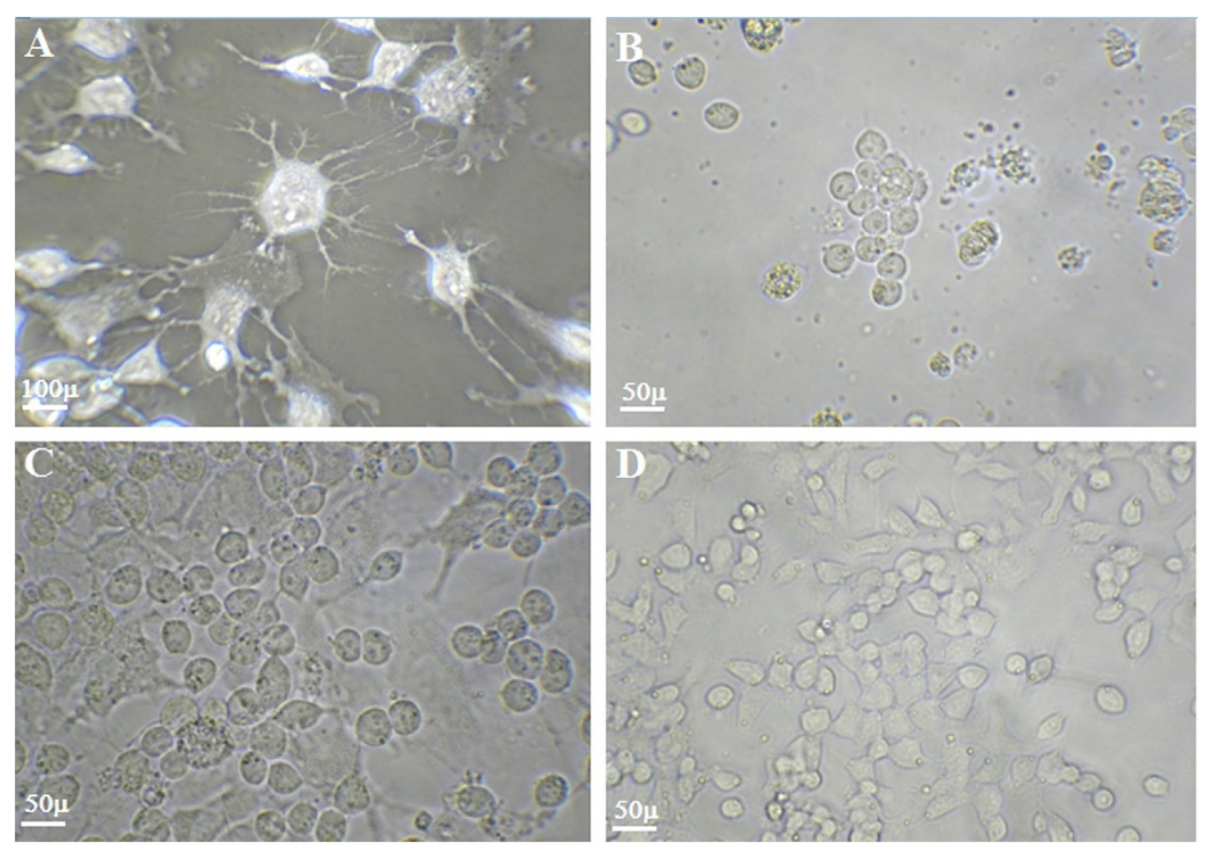

Figure 5 Cultures $\mathrm{P}$ P19 embryonal carcinoma monolayer cells: after treatment with HDA disrupted the organization of the monolayer of P19 cells (A); and addition of S. mutans to monolayer of P19 cells that disrupted the organization of monolayer to a greater extension (B); S. mutans treated with HDA in P19 cultures (C) and not treated culture (D). Magnification in part A is 600X and in the all other images is X400.

mutans cells from adherence to P19 embryonic cells, respectively (Table 1) that determined by gram staining of six well plate cultures.

\section{Discussion}

There are evidences that GtfB and GtfC enzymes are the most important Gtfs related to dental caries [33]. The large size of the gtf genes made transcriptional analysis troublesome, but we decided to investigate $g t f B$ and $g t f C$ genes expression after treatment of the bacterial cultures with a natural antimicrobial compound called HDA. In the present study, it was found that HDA inhibited $g t f B$ and $g t f C$ mRNA transcription and expression. Also it was a good adherence inhibitor of $S$. mutans.

Table 1 Inhibitory effect of HDA on S. mutans adherence to the P19 cell

\begin{tabular}{|c|c|c|}
\hline HDA concentration & Log of Cell count & Percent of preventive \\
\hline$\mu \mathrm{g} \mathrm{ml}^{-1}$ & per Well & adherence \\
\hline 0.00 & 6 & 0.00 \\
\hline 100 & 5.28 & 12 \\
\hline 200 & 4.14 & 31 \\
\hline 500 & 2.46 & 59 \\
\hline 1000 & 2.34 & 61 \\
\hline
\end{tabular}

The $\mathrm{pH}$ of the all experiments set between (7-7.5). *Significant differences were tested by analysis of variance (ANOVA). $p \leq 0.05$.
It was found that the nutrient content of the media culture regulates the progression of biofilms in organisms [34]. Biosynthesis of glucan polymers is critical for the adherence of $S$. mutans to the surfaces; hence, we tested HDA effect on S. mutans attachment quality to the eukaryotic cell surfaces. Because the levels of mRNA is significantly higher in early than in the late exponential phase [35], our study was done based on early exponential phase of $S$. mutans cultures. Despite the fact that our model does not resemble exactly the microbial community found in dental plaques, yet it is profitable model for our investigations.

It was established that the glycolysis and fermentation yield acids that can acidify the biofilms and increase the availability of sucrose [36]. Differential analysis of the S. mutans grown in various nutrient revealed alterations in the genes expression involved in biofilm formation. Also production of glycolytic enzymes could regulate the expression of $g t f$ genes [37]. The $g t f$ genes are induced in response to decreasing $\mathrm{pH}$ of the biofilms and/or in response to the presence of a metabolizable sucrose [38]. Studies on $S$. mutans, using real time RT-PCR, showed two fold increase of gtf mRNA expression in the presence of sucrose [39]. Our real time RT-PCR assay revealed significant decrease in $g t f B$ and $g t f C$ expression after HDA treatment in spite of sucrose addition (Figure 3), supporting HDA as a negative transcriptional regulator of the sucrose dependent activity. However the concentration 
of sucrose has influence in the $\mathrm{pH}$ and $g t f$ genes regulation [40] the present results showed that the $\mathrm{pH}$ effect can be reversed by the HDA treatment (Figure 3 ).

The influence of HDA on $g t f$ transcriptional levels also affected the levels of GtfB and GtfC proteins in the cultures supernatant. Western blot analysis of GtfB and GtfC enzymes indicated that significantly less Gtfs were present in the cultures of $S$. mutans grown in the presence of HDA than for cells grown without treatment (Figure 4). Ooshima and colleagues reported that an optimal GtfB/GtfC ratio is necessary for appropriate colonization in vitro [41], hence divergence from this proportional relation could compromise the adherence of the treated bacteria to the cells as seen in Table 1 .

Previously we found that high concentrations of RJ could inhibit the growth of $S$. mutans but also in lower concentrations it was inhibited gtf genes expression [42]. Findings of this study implied that HDA could penetrate into $S$. mutans and kill the organism as tested by time-kill kinetic assay (Figure 2). The mechanism by which the HDA inhibits the expression of $g t f B$ and $g t f C$ and decreases water insoluble glucan is probably related to the binding to their promoters, blocking RNA synthesis and their expression.

The down regulation of the $g t f B$ and $g t f C$ genes is responsible for the easily detachable biofilm phenotype and decrease in the attachment power of the organisms to the P19 cell surfaces (Figure 5C) in comparison to the untreated bacterial cultures (Figure $5 \mathrm{~B}$ ). By reduction in glucan levels there is no more binding substrate that may prohibits $\alpha-1,6$ glucan dependent biomass aggregation. It has been shown that HDA stimulates collagen production and enhances deposition of collagen in the dermis [43]. Our investigation revealed that HDA decreased the proliferation of P19 embryonic cells but morphologic changes also occurred while neuron like cells were observed by phase contrast microscopy (Figure 5A). After HDA treatment of S. mutans the invasion of P19 embryonal cells was decreased after $6 \mathrm{~h}$ of incubation under the growth conditions described previously (Table 1). Concentration of $500 \mu \mathrm{g}$ ml-1 of HDA could inhibit adherence of $S$. mutans by $59 \%$ (Table 1 ). By preventing adhesion of pathogenic bacteria to their host cells; decreases amount of colonization and in this way reduces the extent of pathogenicity.

The P19 embryonic cell invasion assay developed for testing of HDA towards selected S. mutans represents an attempt to recreate environmental conditions that could be compared to the other eukaryotic cells, and may develop a new model for testing the effect of pharmaceutical compounds on pathogens.

\section{Conclusion}

In conclusion 10-hydroxy-2-decenoic acid treatment could down-regulate the $g t f B$ and $g t f C$ genes expression in S. mutans. Also it could decrease adherence of $S$. mutans to the P19 cells surfaces. Future studies will focus on differential display PCR and microarray analysis to reveal additional $S$. mutans genes that are subjected to HDA effects. This hypothesis will encourage our understanding of gene regulation and signal transduction in S. mutans, and facilitate the development of therapeutic approaches to control formation of the plaque biofilms and dental caries.

\section{Abbreviations \\ HDA: Hydroxy decenoic acid; RJ: Royal jelly; S. mutans: Streptococcus mutans; Gtf: Glucosyltransferase; RT-PCR: Reverse transcriptase polymerase chain reaction; HRP: Horse reddish peroxidase; DMEM: Dulbecco's Modified Eagle's Medium; FCS: Fetal Calf Serum; PBS: Phosphate Buffer saline.}

\section{Competing interests}

The authors declare that they have no competing interests.

\section{Authors' contributions}

BY performed culture, treatment and gene extraction. SG designed experiments, interpreted results. ARL performed SDS PAGE and Western blot analysis. NA designed primers, performed real time PCR and interpreted gene expression profile. JV interpreted results, drafted manuscript. ASH conducted experiments, Critical revision to manuscript, and final draft of manuscript. All authors read and approved the final manuscript.

\section{Author details}

${ }^{1}$ School of Advanced Medical Technologies, Tehran University of Medical Sciences (TUMS), Tehran, Iran. ${ }^{2}$ School of Medicine, Tabriz University of Medical Sciences, Tabriz, Iran. ${ }^{3}$ Periodontology Department, Shahid Beheshti University of Medical Sciences, Tehran, Iran. ${ }^{4}$ Department of Applied Cell Sciences, School of Advanced Technologies in Medicine, Tehran University of Medical Sciences (TUMS), Tehran, Iran. ${ }^{5}$ Tissue Engineering and Stem cell department, Research center for Science and Technology in Medicine (RCSTiM), Tehran University of Medical Sciences (TUMS), P.O.Box: 1998896953, Tehran, Iran.

Received: 6 February 2012 Accepted: 8 July 2012

Published: 28 July 2012

\section{References}

1. Hamilton IR, Bowden GH: Oral microbiology. In Encyclopedia of microbiology. Edited by Lederberg J. San Diego, Calif: Academic Press; 2000:466-480.

2. Shoae-Hassani A, Amirmozafari N, Ordouzadeh N, Ghaemi A: Volatile components of Camellia sinensis inhibit growth and biofilm formation of oral streptococci. Pak J Bio/ Sci 2008, 11(10):1336-1341.

3. Slots J, Rams TE, Listgarten MA: Yeasts, enteric rods and pseudomonads in the subgingival flora of severe adult periodontitis. Oral Microbiol Immunol 1988, 3:47-52

4. Järvensivu A, Hietanen J, Rautemaa R, Sorsa T, Richardson M: Candida yeasts in chronic periodontitis tissues and subgingival microbial biofilms in vivo. Oral Dis 2004, 10:106-112.

5. Van Winkelhoff AJ, Rams TE, Slots J: Systemic antibiotic therapy in periodotitics. Periodontol 1996, 10:45-78.

6. Rams TE, Flynn MJ, Slots J: Subgingival microbial associations in severe human periodontitis. Clin Inf Dis 1997, 25(Suppl. 2):224-226.

7. Kroes I, Lepp PW, Relman DA: Bacterial diversity within the subgingival crevice. Proc Natl Acad Sci USA 1999, 96:14547-14552.

8. Walsh LJ: Dental plaque fermentation and its role in caries risk assessment. Int Dentist 2010, 8(5):34-40.

9. Meurman JH: Dental infections and general health. Quintessence Int 1997 28:807-811.

10. Darvean RP, Tanner A, Page RC: The microbial challenge in periodontitis. Periodontol 1997, 14:12-32.

11. Marsh PD, Bradshaw DJ: Dental plaque as a biofilm. J Ind Microbio/ 1995, 15:169-175 
12. Kuramitsu HK: Virulence factors of mutans streptococci: role of molecular genetics. Crit Rev Oral Biol Med 1993, 4:159-176.

13. Yamashita Y, Bowen WH, Burne RA, Kuramitsu HK: Role of the Streptococcus mutans gtf genes in caries induction in the specificpathogen-free rat model. Infect Immun 1993, 61:3811-3817.

14. Klein Ml, De Baz L, Agidi S, Lee H, Xie G, Lin AH, Hamaker BR, Lemos JA, Koo $H$ : Dynamics of Streptococcus mutans transcriptome in response to starch and sucrose during biofilm development. PLoS One 2010, 5:e13478.

15. Aoki H, Shiroza T, Hayakawa M, Sato S, Kuramitsu HK: Cloning of a Streptococcus mutans glucosyltransferase gene coding for insoluble glucan synthesis. Infect Immun 1986, 53:587-594.

16. Hanada N, Kuramitsu HK: Isolation and characterization of the Streptococcus mutans gtfC gene, coding for synthesis of both soluble and insoluble glucans. Infect Immun 1988, 56:1999-2005.

17. Mateescu C, Barbulescu D: Enhanced nutritive, functional and therapeutic action of combined bee products in complex food supplements. Roman Biotechnol Lett 1999, 4:163-172

18. Biliková K, Hanes J, Nordhoff E, Saenger W, Klaudiny J, Simuth J: Apisimin, a new serine-valinerich peptide from honeybee (Apis mellifera $\mathrm{L}$.) royal jelly: purification and molecular characterization. FEBS Lett 2002, 528:125-129.

19. Schmitzova J, Klaudiny J, Albert S, Schroeder W, Schreckengost W, Hanes J: A family of major royal jelly proteins of the honeybee Apis mellifera. Cell Mol Life Sci J 1998, 54:1020-1030.

20. Lees P, Shojaee Aliabadi F: Rational dosing of antimicrobial drugs: animals versus humans. Int J Antimicr Agents 2002, 19:269-284.

21. Weston RJ, Brocklebank LK, Lu Y: Identication and quantitative levels of antibacterial components of some New Zealand honeys. Food Chem J 2000, 70:427-435.

22. Manfredi R, Chiodo F: The effects of alternative treatments for HIV disease on recommended pharmacological regimens. Int I Antimicr Agents 2000, 13:281-285.

23. Takahashi K, Koshino H, Esumi Y, Tsuda E, Kurosawa K: SW-163 C and E, novel anti-tumor depsi peptides produced by Streptomyces sp. J Antibiotics 2001, 54:622-627.

24. Genc M, Aslan A: Determination of trans-10-hydroxy-2-decenoic acid content in pure royal jelly and royal jelly products by column liquid chromatography. J Chromatography 1999, 839:265-268.

25. Kitahara T, Sato N, Ohya Y, Shinta H, Hori K: The inhibitory effect of hydroxyl acids in royal jelly extract on sebaceous gland lipogenesis. $J$ Derm Sci 1995, 10:75-79.

26. Martindale PK: Thirty second edition the complete drug reference. Printed in US by Taunton Massachusetts: The pharmaceutical press London, UK; 1999:1626.

27. Townsend GF, Brown WH, Felauer EE, Hazlett B: Studies on the in vitro antitumor activity of fatty acids. IV. The esters of acids closely related to 10-hydroxy-2-decenoic acids from royal jelly against transplantable mouse leukemia. Canadian J Biochem Physiol 1961, 39:1765-1770.

28. Koya-Miyata S, Okamoto I, Ushio S, Iwaki K, Ikeda M, Kurimoto M: Identification of a collagen production promoting factor from an extract of royal jelly and its possible mechanism. Biosci Biotechnol Biochem 2004, 68(4):767-773

29. National Committee for Clinical Laboratory Standards: Methods for determining bactericidal activity of antimicrobial agents. Tentative standard M26-T. Wayne, Pa: National Committee for Clinical Laboratory Standards; 1992.

30. Shoae-Hassani A, Amirmozafari N, Ghaemi A: Virulence increasing of Salmonella typhimurium in Balb/c mice after heat stress induction of phage shock protein A. Curr Microbiol 2009, 59:446-450.

31. Cheng Y, Zhizhin I, Perlman RL, Mangoura D: Prolactin induced cell proliferation in $\mathrm{PC} 12$ cells depends on JNK but not ERK activation. J Biol Chem 2000, 275:23326-23332.

32. Abranches $J$, Zeng $L$, Bélanger $M$, Rodrigues $P H$, Simpson-Haidaris PJ, Akin D, DunnJr WA, Progulske-Fox A, Burne RA: Invasion of human coronary artery endothelial cells by Streptococcus mutans OMZ175. Oral Microbiol Immunol 2009, 24(2):141-145.

33. Venkitaraman AR, Vacca-Smith AM, Kopec LK, Bowen WH: Characterization of glucosyltransferaseB, GtfC, and GtfD in solution and on the surface of hydroxyapatite. J Dent Res 1995, 74:1695-1701.

34. Carlson J: Growth and nutrition as ecological factors. In Oral bacterial ecology: the molecular basis. Edited by Kuramitsu HK, Ellen RP. Wymondham: Horizon Scientific Press; 2000:67-130.
35. Gilmore KS, Srinivas P, Akins DR, Hatter KL, Gilmore MS: Growth, development, and gene expression in a persistent Streptococcus gordonii biofilm. Infect Immun 2003, 71:4759-4766.

36. Shemesh M, Tam A, Feldman M, Steinberg D: Differential expression profiles of Streptococcus mutans $\mathrm{ftf}$, gtf and vicR genes in the presence of dietary carbohydrates at early and late exponential growth phases. Carbohydrate Res 2006, 341:2090-2097.

37. Wexler DL, Hudson MC, Burne RA: Streptococcus mutans fructosyltransferase $(f t f)$ and glucosyltransferase ( $g t f B C$ ) operon fusion strains in continuous culture. Infect Immun 1993, 61:1259-1267.

38. Koo H, Hayacibara MF, Schobel BD, Cury JA, Rosalen PL, Park YK: Inhibition of Streptococcus mutans biofilm accumulation and polysaccharide production by apigenin and $t t$-farnesol. J Antimicr Chemother 2003, 52:782-789

39. Li Y, Burne RA: Regulation of the gtfBC and ftf genes of Streptococcus mutans in biofilms in response to $\mathrm{pH}$ and carbohydrate. Microbiology 2001, 147:2841-2848.

40. Fujiwara T, Hoshino T, Ooshima T, Hamada S: Differential and quantitative analyses of mRNA expression of glucosyltransferases from Streptococcus mutans MT8148. J Dent Res 2002, 81(2):109-113.

41. Ooshima T, Matsumura M, Hoshino T, Kawabata S, Sobue S, Fujiwara T: Contributions of three glucosyltransferases to sucrose dependent adherence of Streptococcus mutans. J Dent Res 2001, 80:1672-1677.

42. Shoae-Hassani A: Royal jelly's effect on glucosyltransferase expression in Streptococcus mutans. Helsinki, Finland: 19th European congress of clinical microbiology and infectious diseases (ECCMID): 2009:1628.

43. Browngardt CM, Wen ZT, Burne RA: RegM is required for optimal fructosyltransferase and glucosyltransferase gene expression in Streptococcus mutans. FEMS Microbiol Lett 2004, 240:75-79.

doi:10.1186/1476-0711-11-21

Cite this article as: Yousefi et al: Hydroxy decenoic acid down regulates gtfB and gtfC expression and prevents Streptococcus mutans adherence to the cell surfaces. Annals of Clinical Microbiology and Antimicrobials 2012 11.21.

\section{Submit your next manuscript to BioMed Central and take full advantage of:}

- Convenient online submission

- Thorough peer review

- No space constraints or color figure charges

- Immediate publication on acceptance

- Inclusion in PubMed, CAS, Scopus and Google Scholar

- Research which is freely available for redistribution 